\title{
A Vision for Spaceflight Reliability: NASA's Objectives Based Strategy
}

Frank Groen, John Evans - NASA OSMA

Tony Hall - ISL

Presented at RAMS 2015 


\section{NASA Challenges}

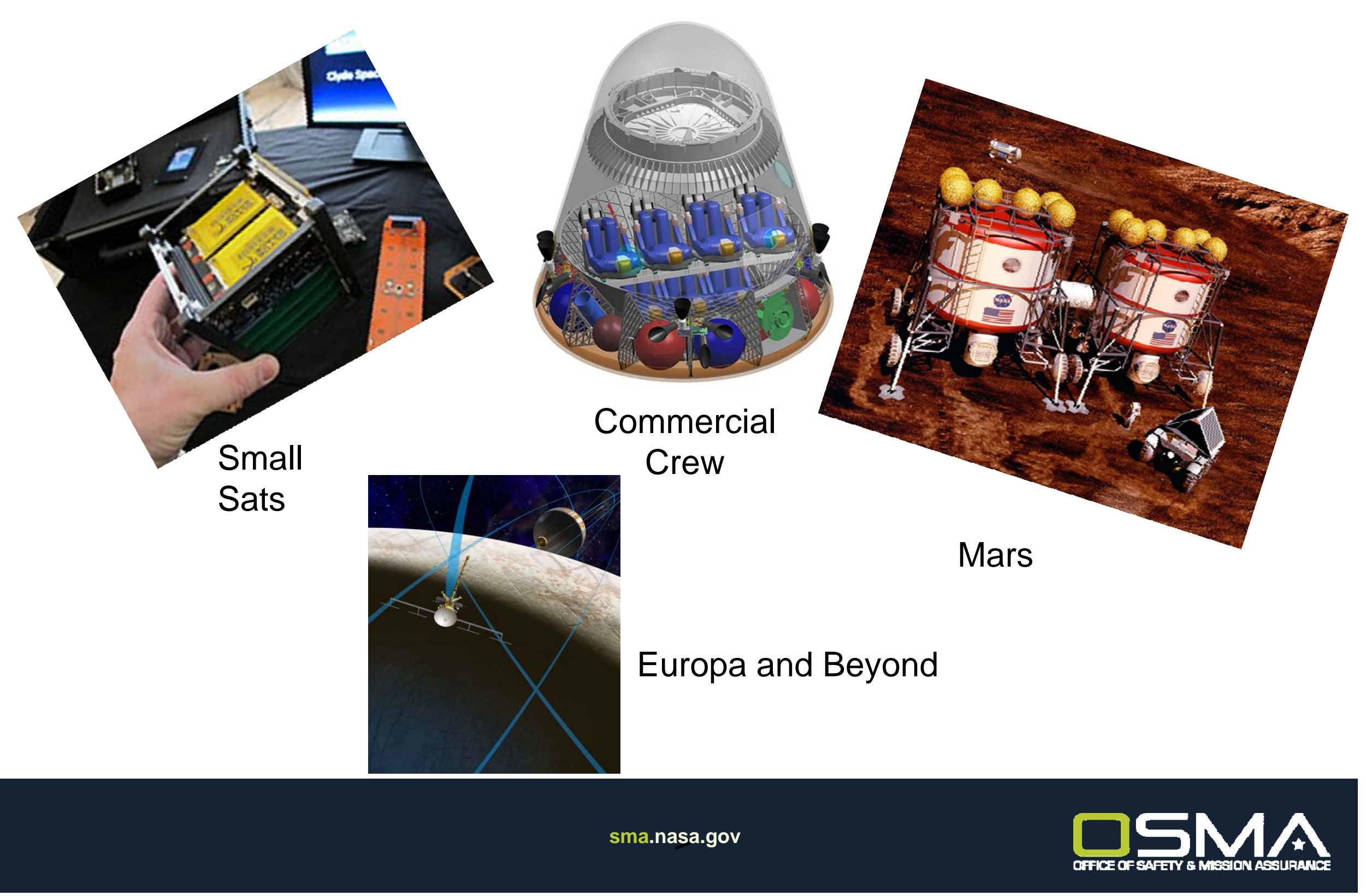




\section{MBSE}

NASA INTEGRATEd MOdEL-CENTRIC ARCHITECTURE NASA NIMA

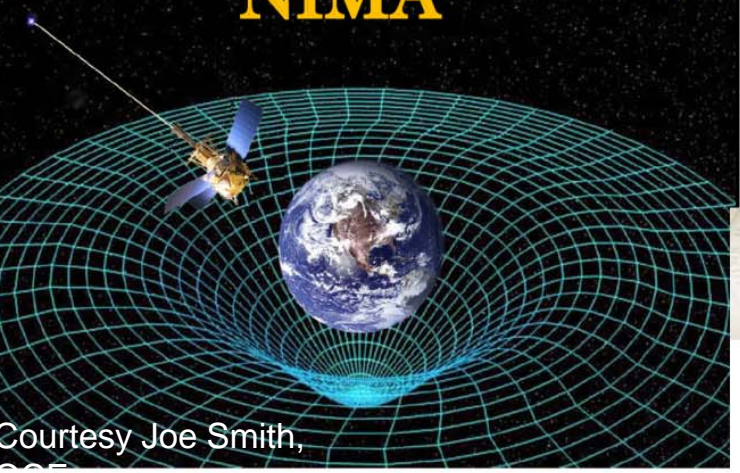

NASA OCE

direction will enable model centric capability

Our products may need to be different in a model based environment

4 Pillars of SysML - ABS Example

\section{西}

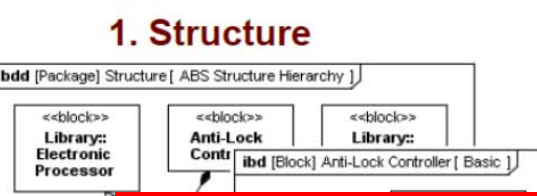

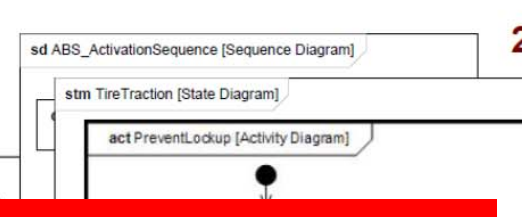

Decisions should not defrinum be made without our insight and oversight
2. Behavior FMEA Hazard Analysis

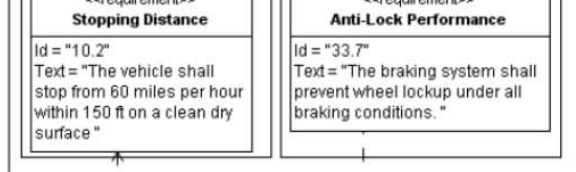

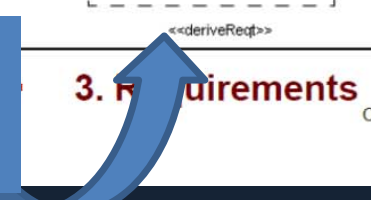

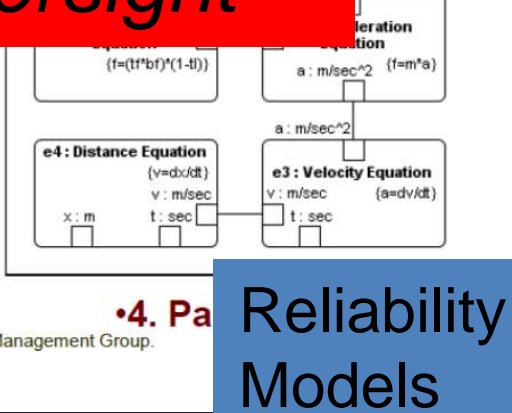




\section{Mission Assurance Challenges}

- NASA's Mission Assurance faces challenges

- Changing missions

- Changing acquisition models

- Changing engineering practices

- Changing technology

- We must reconsider our practices to stay relevant

- Don't necessarily hang on to 'proven' practices

- Consider the intent behind R\&M methods and techniques 


\section{"Subset of Considerations"}

- Focus on the what:

- Emphasize R\&M objectives and related strategies

- Leave choice of methods and techniques to implementing organizations

- Allow for innovation and adaptation to new engineering practices 


\section{Decomposition of R\&M Objectives}

\section{R\&M Objectives Structure - Top-Level}

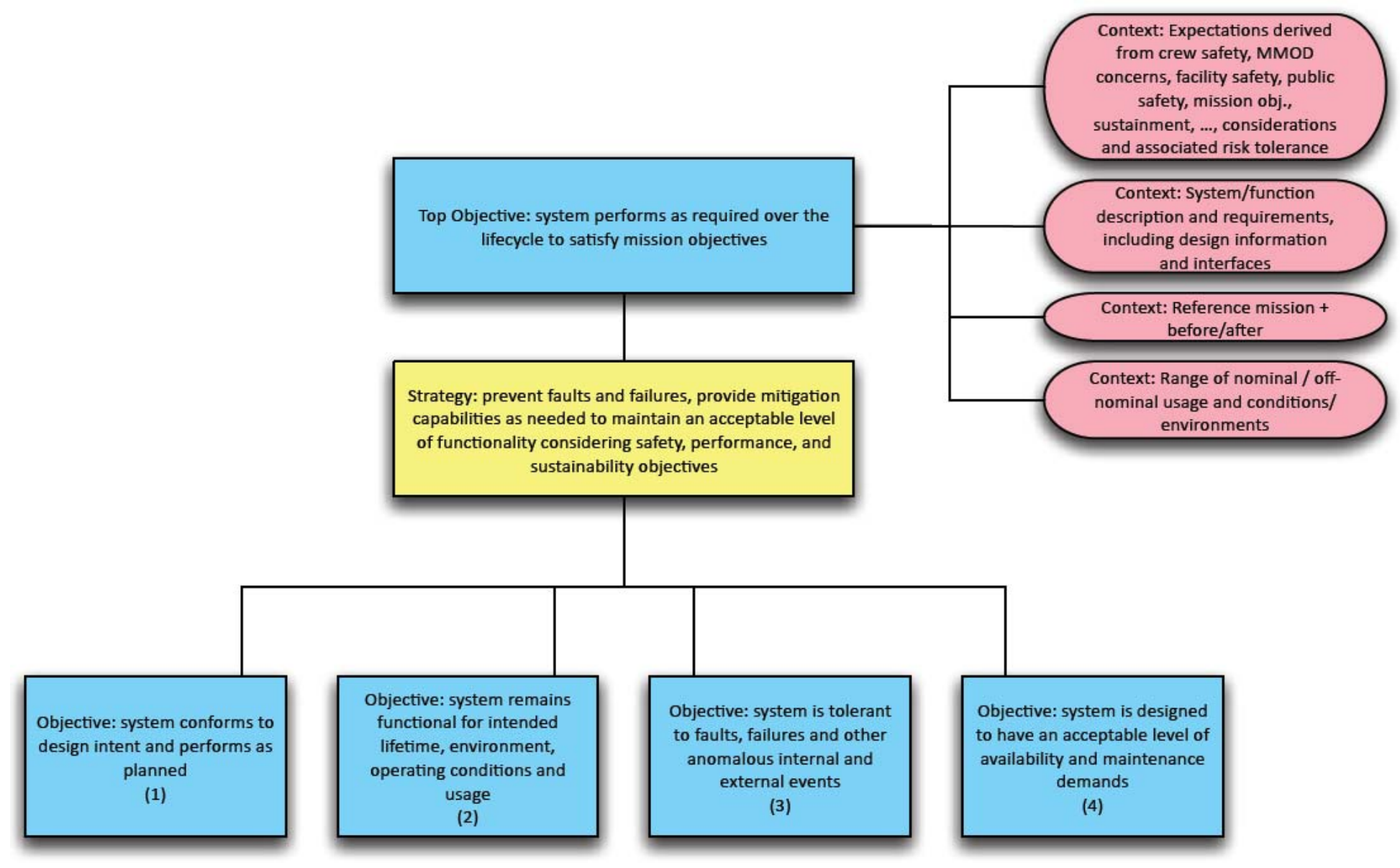




\section{R\&M Hierarchy Sub-Obj. 2}

Objective: System remains functional for intended lifetime, environment, operating conditions and usage (2)
Context: Description of including static, cyclical, and randomly varying loads
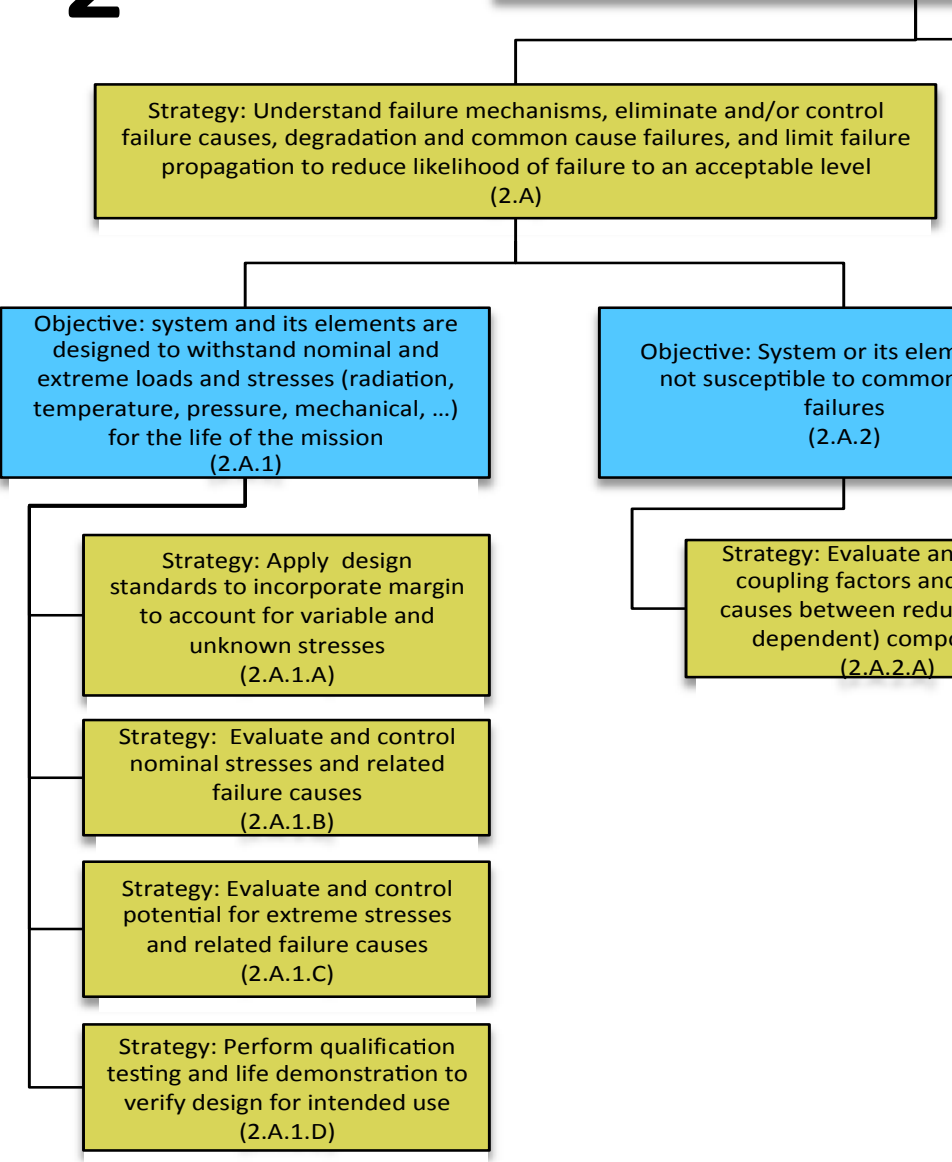

hanisms, eliminate and/or control common cause failures, and limit failure (2.A) fure to an acceptable level (19)

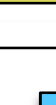

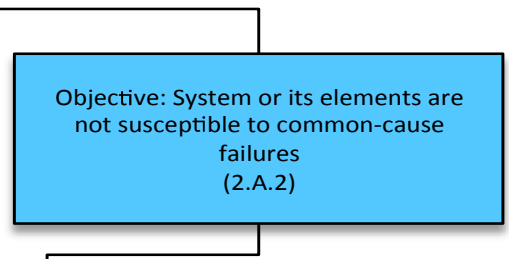

Strategy: Assess quantitative reliability measures and recommend or erations (2.B)

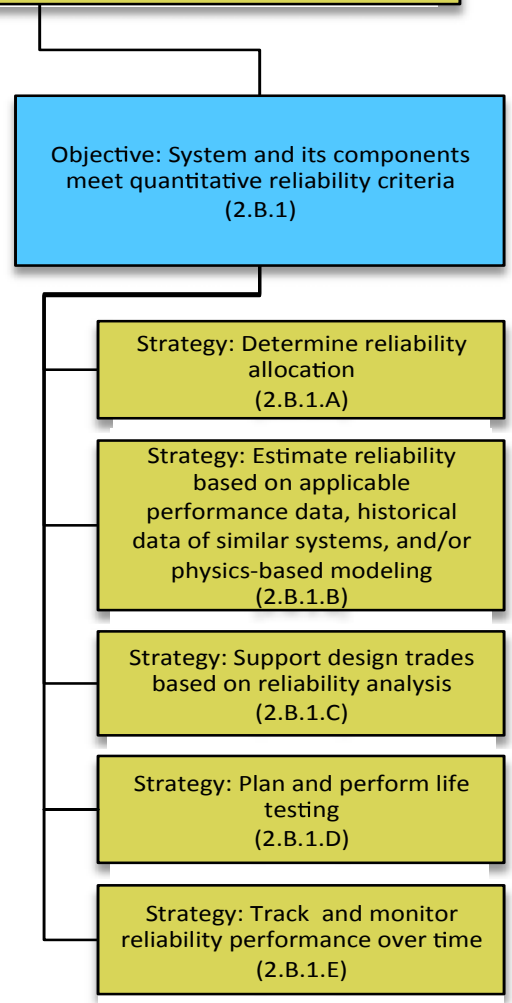




\section{Laying the Foundation}

- Logically decompose top-level R\&M objective

- Use elements of the Goal Structuring Notation

- Structure shows why strategies are to be applied

- Structure forms basis for a proposed R\&M standard

- Specifies the technical considerations to be addressed by projects

- Forms basis for evaluation of plans, design, and assurance products 


\section{Summary}

- Changes in missions, acquisition/engineering practices, and technology challenge proven R\&M practices

- Define R\&M objectives and strategies to enable adaptation and innovation

- Logically decompose the top-level R\&M objective to identify the elements of an R\&M argument 


\section{Final Thoughts}

- MBSE is not the rationale for the proposed approach, but is considered to help devise R\&M tools and methods within MBSE contexts.

- Community will have to work towards open standards for documenting R\&M arguments and evidence

- As part of broader assurance framework

- Enable infrastructure of MBSE-compatible R\&M tools 